\title{
Biodistribution and endocytosis of ICAM-I- targeting antibodies versus nanocarriers in the gastrointestinal tract in mice
}

This article was published in the following Dove Press journal:

International Journal of Nanomedicine

31 July 2012

Number of times this article has been viewed

Viraj Mane'

Silvia Muro',2

'Institute for Bioscience and Biotechnology Research, ${ }^{2}$ Fischell Department of Bioengineering, University of Maryland, College Park, MD, USA
Correspondence: Silvia Muro

Institute for Bioscience and

Biotechnology Research, Plant Sciences

Building, Room 5 I 5, University of

Maryland, College Park,

MD 20742-4450, USA

Tel +I 30I 4054777

Fax + I 30I 3 I4 9075

Email muro@umd.ed
Abstract: Drug delivery to the gastrointestinal (GI) tract is key for improving treatment of GI maladies, developing oral vaccines, and facilitating drug transport into circulation. However, delivery of formulations to the GI tract is hindered by $\mathrm{pH}$ changes, degradative enzymes, mucus, and peristalsis, leading to poor GI retention. Targeting may prolong residence of therapeutics in the GI tract and enhance their interaction with this tissue, improving such aspects. We evaluated nanocarrier (NC) and ligand-mediated targeting in the GI tract following gastric gavage in mice. We compared GI biodistribution, degradation, and endocytosis between control antibodies and antibodies targeting the cell surface determinant intercellular adhesion molecule 1 (ICAM-1), expressed on GI epithelium and other cell types. These antibodies were administered either as free entities or coated onto polymer NCs. Fluorescence and radioisotope tracing showed proximal accumulation, with preferential retention in the stomach, jejunum, and ileum; and minimal presence in the duodenum, cecum, and colon by 1 hour after administration. Upstream (gastric) retention was enhanced in NC formulations, with decreased downstream (jejunal) accumulation. Of the total dose delivered to the GI tract, $\sim 60 \%$ was susceptible to enzymatic (but not $\mathrm{pH}-$ mediated) degradation, verified both in vitro and in vivo. Attenuation of peristalsis by sedation increased upstream retention (stomach, duodenum, and jejunum). Conversely, alkaline $\mathrm{NaHCO}_{3}$, which enhances GI transit by decreasing mucosal viscosity, favored downstream (ileal) passage. This suggests passive transit through the GI tract, governed by mucoadhesion and peristalsis. In contrast, both free anti-ICAM and anti-ICAM NCs demonstrated significantly enhanced upstream (stomach and duodenum) retention when compared to control IgG counterparts, suggesting GI targeting. This was validated by transmission electron microscopy and energy dispersive X-ray spectroscopy, which revealed anti-ICAM NCs in vesicular compartments within duodenal epithelial cells. These results will guide future work aimed at improving intraoral delivery of targeted therapeutics for the treatment of GI pathologies.

Keywords: gastrointestinal tract, ICAM-1 targeting, endocytosis, antibody, polymer nanocarriers

\section{Introduction}

The gastrointestinal (GI) epithelium is a target for the treatment of GI maladies, such as ulcer, Crohn's disease, infection, and GI cancer, where local drug activity is required. ${ }^{1}$ Additionally, uptake by the GI epithelium can facilitate transport of drugs into the circulation. ${ }^{2,3}$ Delivery to the GI tract via oral administration is one of the best tolerated methods for clinical drug delivery, with high patient compliance. ${ }^{4,5}$ However, formulations for GI delivery face numerous barriers, including $\mathrm{pH}$ transitions, digestive enzymes, mucosal shedding, and peristalsis, hindering GI drug retention. ${ }^{1,6-8}$ 
When transepithelial delivery is intended, intercellular tight junctions in the GI epithelial layer prevent access to the underlying vasculature, further limiting the bioavailability of oral drugs. ${ }^{2,3}$

These aspects can be improved by drug targeting strategies, eg, by ligand-specific attachment, $\mathrm{pH}-$ dependent disintegration, protective coatings, mucoadhesive approaches, or increased absorption for improved bioavailability. ${ }^{1,7,9-12}$ Many strategies exploit the binding of natural ligands to their receptors on GI cells (lectins, mannose, vitamin $\mathrm{B}_{12}$, thiamine, etc) or antibodies that recognize GI surface markers, which in some cases also induce uptake into cells. ${ }^{13-17}$

Targeting approaches can in theory be combined with the use of protective compounds for oral formulations, such as chitosan, ${ }^{18-20}$ controlled-release hydrogels, ${ }^{8,21,22}$ and $\mathrm{pH}$-sensitive polymers. ${ }^{23-25}$ Strategies to facilitate mucus penetration can be additionally used, such as incorporation of chitosan, ${ }^{18,19}$ polyethylene glycol, ${ }^{12,26}$ surfactants, ${ }^{27,28}$ or mucolytic agents. ${ }^{6,9,29}$ These strategies have also been explored in conjunction with nanocarriers (NCs). NCs offer advantages for drug delivery since their properties can be controlled by engineering and/or chemical means, allowing versatility in material, size, architecture, stability, bioavailability, drug transport, release, etc. ${ }^{30-32} \mathrm{NCs}$ can also be modified with affinity moieties for improved ligand-dependent targeting and have been shown to increase drug stability, targeting, and transport in the GI tract. ${ }^{7,12,26,33}$

A potential target for ligand-mediated GI delivery is intercellular adhesion molecule 1 (ICAM-1), a transmembrane glycoprotein expressed on the luminal surface of GI epithelial cells and other cell types. ${ }^{34-36}$ ICAM-1 is upregulated in several disease states, ${ }^{34-36}$ including GI disorders such as bacterial infection, ${ }^{36} \mathrm{Crohn}$ 's disease, ${ }^{37}$ peptic ulcer, ${ }^{38}$ and gastric cancer. ${ }^{39} \mathrm{We}$ and others have shown that, upon intravenous administration in animal models, ICAM-1 targeting improves biodistribution of diagnostic and therapeutic agents. ${ }^{40-44}$ Furthermore, ICAM-1-targeting NCs can be modulated to display optimal antibody surface density, size, and shape, leading to internalization into cells, which is suitable for intracellular drug transport. ${ }^{45-47}$ In the context of drug delivery in the GI tract, however, ICAM-1 targeting has not been explored.

As a method to improve retention in the GI tract (applicable to drug conjugates and therapeutic NCs), in this study we have explored ligand-specific targeting of free antibodies as well as antibodies coupled to the surface of polymer NCs. We have used fluorescence, radioisotope tracing, transmission electron microscopy, and energy dispersive
X-ray spectroscopy to study binding, uptake, biodistribution, and degradation of nontargeting versus ICAM-targeting antibodies and antibody-coated NC formulations in the GI tract. Taken together, we have described a targeted delivery approach which may improve the efficacy of intraoral therapeutics.

\section{Methods}

\section{Antibodies and reagents}

To minimize potential interaction of antibody Fc fragments with mouse Fc receptors in the gut, all antibodies used in this study were rat IgGs. The ICAM-targeting antibody used was monoclonal rat IgG recognizing mouse ICAM-1 (anti-ICAM), clone YN.1. ${ }^{46}$ Matching control antibodies were non-labeled rat $\mathrm{IgG}$ and fluorescein isothiocyanate (FITC)-labeled rat IgG from Jackson ImmunoResearch Laboratories, Inc (West Grove, PA). FITC-labeled $100 \mathrm{~nm}$ diameter polystyrene particles were from Polysciences, Inc (Warrington, PA) and $100 \mathrm{~nm}$ iron oxide particles coated with goat anti-rat IgG were from Chemicell $\mathrm{GmbH}$ (Berlin, Germany). Phosphate-buffered saline (PBS) was from Gibco (Life Technologies, Carlsbad, CA), bovine serum albumin was from Equitech-Bio, Inc (Kerrville, TX), and $\mathrm{NaHCO}_{3}$ and trichloroacetic acid (TCA) were from Thermo Fisher Scientific (Waltham, MA). Na ${ }^{125} \mathrm{I}$ and Pierce Iodination Beads were from PerkinElmer (Waltham, MA) and Thermo Fisher Scientific, respectively. Simulated gastric fluid (SGF) and simulated intestinal fluid (SIF) were from Cole-Parmer (Vernon Hills, IL), while the corresponding digestive enzymes pepsin and pancreatin were from Sigma-Aldrich (St Louis, MO).

\section{Preparation of antibody-coated nanocarriers}

Antibody-coated NCs were prepared as described. ${ }^{43}$ Briefly, anti-ICAM or control IgG were absorbed onto the surface of $100 \mathrm{~nm}$ FITC-polystyrene particles by incubation in PBS. For biodistribution experiments, the formulations contained $5 \%{ }^{125}$ I-labeled IgG as a radiotracer. ${ }^{43}$ Antibody-coated NCs were separated from non-coated antibodies by centrifugation, and resuspended in PBS or $0.36 \mathrm{M} \mathrm{NaHCO}_{3}$. Bovine serum albumin $(0.3 \%)$ was added to both solutions to better mimic a physiological-like fluid and to help avoid aggregation. We further prevented aggregation by sonicating the preparations at low power (note that this sonication protocol has been shown to minimally affect the NC coat). ${ }^{43}$ This protocol yielded a coating density of $262 \pm 4.4$ antibody molecules per $\mathrm{NC}$, based on ${ }^{125} \mathrm{I}$ measurement in a Wizard ${ }^{2}$ gamma-radiation 
counter (PerkinElmer). The size, polydispersity, and zeta potential of the samples were measured by dynamic light scattering and electrophoretic mobility using the Zetasizer Nano (Malvern, Westborough, MA). Table 1 shows the characterization of these NCs.

Anti-ICAM iron oxide NCs were prepared by mixing antiICAM with $100 \mathrm{~nm}$ iron oxide particles pre-coated with goat anti-rat IgG, followed by magnetic separation from free antiICAM as indicated by the vendor. Final anti-ICAM iron oxide NCs presented a diameter of $132.6 \pm 4.0 \mathrm{~nm}$, polydispersity index of $0.09 \pm 0.02$, and $87 \pm 3.4$ antibody molecules per NC.

\section{Degradation of antibodies and antibody- coated nanocarriers in vitro}

Spontaneous degradation of antibody or antibody-coated NCs under conditions that mimic storage was determined by measuring release of free ${ }^{125}$ Iodine from the samples via TCA precipitation. ${ }^{43}$ This was done after incubation at $4^{\circ} \mathrm{C}$ or $37^{\circ} \mathrm{C}$ for 1 hour or 3 hours in PBS (pH 7.0 or 4.1 ), or $0.36 \mathrm{M}$ $\mathrm{NaHCO}_{3}(\mathrm{pH} 8.2)$, as shown in Table 2. Degradation was also measured from 1 minute to 24 hours in simulated gastric fluid (SGF, pH 1.1) with or without $3.2 \mathrm{mg} / \mathrm{mL}$ pepsin, or simulated intestinal fluid (SIF, pH 6.8) with or without $10 \mathrm{mg} / \mathrm{mL}$ pancreatin, following a protocol detailed by Fu et al. ${ }^{48}$ To complete this study, the size, polydispersity, and zeta potential of NCs in PBS, SGF, or SIF were also measured (Table 1).

\section{Biodistribution and degradation of antibodies and antibody-nanocarriers in vivo}

C57BL/6 wild type mice (Jackson Laboratory, Bar Harbor, $\mathrm{ME}$ ) were fasted for 2-4 hours and then injected intraperitoneally with anesthetic (100 mg ketamine/10 mg xylazine/ $\mathrm{kg}$ body weight) or PBS. Mice ( $\geq 3$ per group) were orally gavaged with $\mathrm{PBS}$ or $0.36 \mathrm{M} \mathrm{NaHCO}_{3}$ containing ${ }^{125} \mathrm{I}-\mathrm{IgG}$ or ${ }^{125} \mathrm{I}$-anti-ICAM $(1.1 \mathrm{mg} / \mathrm{kg})$ to track antibody biodistribution. To track antibody-coated NCs, ${ }^{125} \mathrm{I}-\mathrm{IgG}$ NCs or ${ }^{125} \mathrm{I}$-anti-ICAM $\mathrm{NCs}$ were used $\left(1.1 \mathrm{mg}\right.$ antibody $\left./ \mathrm{kg}, 1.5 \times 10^{13} \mathrm{NCs} / \mathrm{kg}\right)$.
After oral gavage the stomach, duodenum, jejunum, ileum, cecum, and colon were extracted from the animal and their ${ }^{125}$ Iodine content was measured in a gamma-radiation counter (Wizard ${ }^{2}$; PerkinElmer) to determine the percentage of injected dose (\% ID) in each GI compartment. Degradation of antibodies or antibody-coated NCs in homogenized GI sections was assessed using the TCA precipitation method described above. Studies were performed in accordance with IACUC and University of Maryland regulations.

\section{Visualization of antibodies and antibody- coated nanocarriers and energy dispersive X-ray spectroscopy (EDS) analysis}

To visualize passage through the GI tract, mice were gavaged with FITC-labeled $\operatorname{IgG}(33.3 \mathrm{mg} / \mathrm{kg})$ or FITC-labeled IgG $\mathrm{NCs}\left(6.67 \mathrm{mg} \mathrm{IgG} / \mathrm{kg}, 9.0 \times 10^{13} \mathrm{NC} / \mathrm{kg}\right)$ in $0.36 \mathrm{M} \mathrm{NaHCO}_{3}$ buffer. The GI tract was isolated 5 minutes or 30 minutes after administration and imaged on a Bi-O-Vision TVD1000R UV transilluminator (Spectroline; Spectronics Corporation, Westbury, NY). To visualize binding of anti-ICAM NCs to GI tissue, mice were gavaged with FITC-labeled anti-ICAM $\mathrm{NCs}\left(6.67 \mathrm{mg} \mathrm{IgG} / \mathrm{kg}, 9.0 \times 10^{13} \mathrm{NC} / \mathrm{kg}\right)$ in PBS and sacrificed after 15 minutes. Cross-sectional GI tissue fragments were excised throughout the GI tract and rinsed vigorously in PBS and 70\% EtOH to remove nonattached NCs. Tissue sections were fixed in $4 \%$ paraformaldehyde and imaged with a Nikon IX81 microscope (Nikon Inc., Melville, NY) to detect tissue-bound FITC-NCs.

To improve visualization by transmission electron microscopy (TEM), mice were gavaged with anti-ICAM iron oxide NCs instead of polystyrene counterparts, as iron oxide is electron dense. GI tissue fragments were fixed in $2.5 \%$ glutaraldehyde in Millonig's buffer, embedded and sectioned from Spurr's resin blocks, stained with 2\% uranyl acetate and $0.3 \%$ lead citrate, and placed onto copper grids at the University of Maryland Laboratory for Biological Ultrastructure (College Park, MD). ${ }^{43}$ Additionally, antibody-coated iron oxide

Table I Characterization of polymer NCs

\begin{tabular}{lllllll}
\hline NC surface coating: & None & & & IgG & \\
\hline Dispersant: & PBS & SGF & SIF & PBS & SGF & SIF \\
\hline Diameter $(\mathrm{nm})$ & $157.1 \pm 3.5$ & $157.2 \pm 1.4$ & $150.4 \pm 2.3$ & $269.8 \pm 6.3$ & $312.7 \pm 3.6$ & $285.1 \pm 6.9$ \\
PDI & $0.169 \pm 0.009$ & $0.097 \pm 0.008$ & $0.125 \pm 0.010$ & $0.353 \pm 0.013$ & $0.171 \pm 0.009$ & $0.211 \pm 0.013$ \\
Zeta potential $(\mathrm{mV})$ & $-6.4 \pm 0.5$ & $21.6 \pm 0.6$ & $-16.4 \pm 0.8$ & $-7.1 \pm 0.2$ & $17.7 \pm 1.0$ & $-10.0 \pm 0.5$ \\
\hline
\end{tabular}

Notes: Data are mean \pm SEM $(n \geq 3)$.

Abbreviations: NC, nanocarrier; PDI, polydisperity index; PBS, phosphate-buffered solution; SGF, simulated gastric fluid; SIF, simulated intestinal fluid; SEM, standard error of the mean. 
NCs were placed directly onto microscope grids for NC characterization. Imaging was performed at the Laboratory for Biological Ultrastructure on a Zeiss EM 10 CA instrument (Zeiss, Oberkochen, Germany). After carbon-coating the grids, imaging spectroscopy and EDS were conducted using INCAEnergy software (Oxford Instruments, Oxfordshire, UK) at the University of Maryland Nanoscale Imaging, Spectroscopy, and Properties Lab on a JEOL JEM-2100F instrument (JEOL, Tokyo, Japan). For EDS analysis, the indicated regions were queried for iron, oxygen, carbon, and calcium content.

\section{Statistics}

Data were calculated as mean \pm standard error of the mean (SEM). Statistical significance was determined by Student's unpaired $t$-test. For in vitro degradation assays, the regression curves, half-life of enzymatic degradation $\left(t^{1 / 2}\right)$, 24-hour degradation maximum $\left(D_{24 h r}\right)$, and coefficient of determination $\left(\mathrm{R}^{2}\right)$ were derived from Ligand Binding analysis in SigmaPlot 11.0 (Systat Software, Inc, San Jose, CA).

\section{Results}

\section{Biodistribution and degradation of $\lg G$ in the GI tract}

Both antibodies and NC particles displaying antibodies against specific cell surface determinants are commonly used to improve drug bioadhesion to tissues requiring therapeutic intervention or to those involved in transport across cellular barriers in the body. Although this strategy is expected to encounter obstacles in the GI tract (eg, degradation, poor diffusion, etc), antibodies have been shown to overcome these obstacles to some extent. ${ }^{49,50}$

We first visualized passage of fluorescently-labeled control rat IgG through the GI tract by UV transillumination after oral gavage in mice (Figure S1). In contrast to the saline vehicle control, fluorescent IgG was initially visible in more proximal GI regions, transitioning to a less intense signal with a more distal distribution over time. The cecum and colon, however, showed no fluorescence above background levels (data not shown). Radiotracing studies confirmed this distribution. For instance, GI transit of ${ }^{125} \mathrm{I}-\mathrm{IgG} 1$ hour after oral gavage in mice (Figure 1A) showed that, when administered in neutral buffer (PBS), ${ }^{125} \mathrm{I}-\mathrm{IgG}$ was mostly retained in the stomach $(18.7 \% \pm 2.1 \%$ injected dose, “\% ID”), with significant fractions found in the jejunum $(8.3 \% \pm 2.9 \%$ ID) and ileum $(12.3 \% \pm 3.9 \%$ ID), a small fraction located in the duodenum $(1.1 \% \pm 0.3 \%$ ID), and negligible amounts
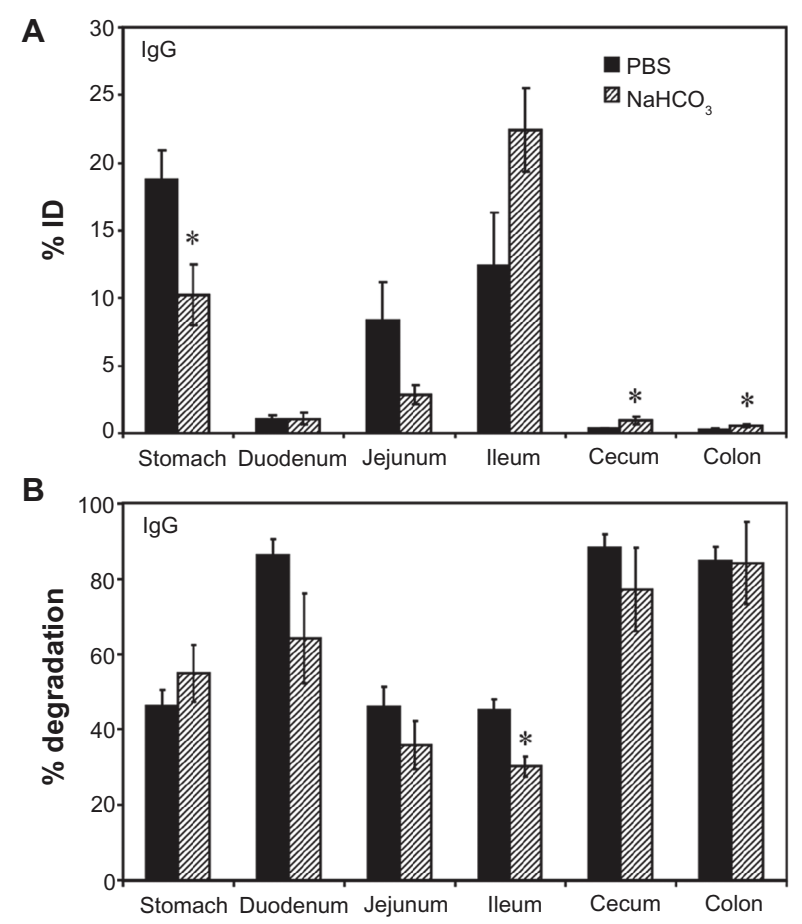

Figure I Biodistribution and degradation of $\operatorname{lgG}$ in the $\mathrm{Gl}$ tract. Mice were orally gavaged with ${ }^{125} \mathrm{I}-\mathrm{lgG}$ in either $\mathrm{PBS}$ or $\mathrm{NaHCO}_{3}$. One hour later, the indicated sections of the GI were harvested and measured for their ${ }^{125}$-content, expressed as \% ID (A). Alternatively, samples were subjected to TCA precipitation to determine the percentage of free ${ }^{125}$ lodine, reflective of antibody degradation (B).

Notes: Data are mean \pm SEM $(n \geq 3)$. ${ }^{*} P<0.05$ between saline and $\mathrm{NaHCO}_{3}$ groups.

Abbreviations: PBS, phosphate-buffered saline; GI, gastrointestinal; TCA, trichloroacetic acid; \% ID, percentage of the total injected dose; SEM, standard error of the mean.

in the cecum and colon $(0.4 \pm 0.04$ and $0.3 \% \pm 0.04 \%$ ID). As a control, mice gavaged with ${ }^{125} \mathrm{I}-\mathrm{IgG}$ under anesthesia to reduce peristalsis (Figure S2A), showed increased retention in more proximal GI regions, including the stomach, duodenum, and jejunum (1.8-, 3.9-, and 2.5-fold increase, respectively).

Importantly, TCA precipitation (Figure 1B) revealed that a substantial fraction of ${ }^{125} \mathrm{I}-\mathrm{IgG}$ in the stomach, jejunum, and ileum remained undegraded in vivo by 1 hour $(53.7 \% \pm 4.2 \%$, $53.9 \% \pm 5.3 \%$, and $54.8 \% \pm 2.9 \%$, respectively). The majority of the signal obtained from the duodenum, cecum, and colon corresponded to highly degraded ${ }^{125}$ Iodine $(86.4 \% \pm 4.1 \%$, $88.2 \% \pm 3.7 \%$, and $84.9 \% \pm 3.7 \%$, respectively). Compared with $\mathrm{PBS}$, oral gavage in alkaline $\mathrm{NaHCO}_{3}$ buffer ( $\mathrm{pH}$ 8.2) did not significantly affect the degradation pattern of ${ }^{125} \mathrm{I}-\mathrm{IgG}$ (Figure 1B), despite reducing retention in the stomach (1.8-fold reduction) in favor of transit to the ileum (1.8-fold increase; Figure 1A). Stomach degradation of ${ }^{125} \mathrm{I}-\mathrm{IgG}$ was unaffected in sedated mice, despite the fact that retention in this compartment is significantly 
favored in sedated animals (Figure S2). Altogether, these data indicate the presence of nondegraded antibody in relatively proximal GI regions (stomach, jejunum, ileum), while distal GI regions (cecum and colon) accumulate only degraded antibody products. Degradation was most apparent in the duodenum despite the use of alkaline buffer, and therefore is likely due to enzymatic action rather than acidity per se.

\section{Enzyme- and $\mathrm{pH}$-dependent degradation of IgG in vitro}

To explore the aforementioned hypothesis regarding degradation, we assessed the stability of ${ }^{125} \mathrm{I}-\mathrm{IgG}$ in vitro. As shown in Table 2, ${ }^{125} \mathrm{I}$-IgG was highly resistant $(<3 \%$ degradation) to changes in temperature $\left(4^{\circ} \mathrm{C}\right.$ versus $\left.37^{\circ} \mathrm{C}\right)$ and $\mathrm{pH}$ (acidic $\mathrm{pH} 4$, neutral $\mathrm{pH} 7$, or basic $\mathrm{pH} 8.2$ ) up to 3 hours, suggesting that degradation depends on other factors such as digestive enzymes. Confirming this (Figure 2), ${ }^{125} \mathrm{I}-\mathrm{IgG}$ underwent minimal degradation $(<4 \%)$ when incubated for 24 hours at $37^{\circ} \mathrm{C}$ in simulated gastric fluid (SGF; $\mathrm{pH}$ 1.1) or intestinal fluid (SIF; pH 6.8) in the absence of enzymes. However, the presence of pepsin within SGF or pancreatin within SIF caused rapid and significant ${ }^{125} \mathrm{I}$ - $\operatorname{IgG}$ degradation $(47.2 \% \pm 1.1 \%$ and $8.2 \% \pm 0.6 \%$ degradation at 1 minute, respectively). Degradation was faster in the case of pepsin-containing SGF ( $\mathrm{t}^{1} / 2=0.6$ minutes; $\left.\mathrm{D}_{24 \mathrm{hr}}=75.3 \%\right)$ versus pancreatin-containing SIF $(\mathrm{t} 1 / 2=348.0$ minutes; $\mathrm{D}_{24 \mathrm{hr}}=83.4 \%$ ). These results support the hypothesis that degradation is largely mediated by digestive enzymes rather than $\mathrm{pH}$. Also, it is likely that the large fraction of degraded ${ }^{125} \mathrm{I}-\mathrm{IgG}$ observed in the duodenum may arise from (a) enzymatic degradation within the duodenum itself, and (b) duodenal migration of antibody previously degraded in the stomach.

Table $2 \%$ degradation of $\lg G$ and $\lg G N C s$ in vitro

\begin{tabular}{|c|c|c|c|c|}
\hline & \multicolumn{2}{|l|}{ IgG } & \multicolumn{2}{|l|}{ IgG NCs } \\
\hline & $\mathrm{I} \mathrm{hr}$ & $3 \mathrm{hr}$ & $\mathrm{I} \mathrm{hr}$ & $3 \mathrm{hr}$ \\
\hline \multicolumn{5}{|c|}{ PBS pH 7} \\
\hline $4^{\circ} \mathrm{C}$ & $2.4 \pm 0.12$ & $2.4 \pm 0.14$ & $1.5 \pm 0.23$ & $1.9 \pm 0.12$ \\
\hline $37^{\circ} \mathrm{C}$ & $2.4 \pm 0.12$ & $2.5 \pm 0.12$ & $1.7 \pm 0.15$ & $2.3 \pm 0.07$ \\
\hline \multicolumn{5}{|c|}{ PBS pH 4} \\
\hline $4^{\circ} \mathrm{C}$ & $2.4 \pm 0.10$ & $2.4 \pm 0.04$ & $1.4 \pm 0.15$ & $1.6 \pm 0.17$ \\
\hline $37^{\circ} \mathrm{C}$ & $2.2 \pm 0.14$ & $2.3 \pm 0.08$ & $1.7 \pm 0.24$ & $1.6 \pm 0.25$ \\
\hline \multicolumn{5}{|c|}{$\mathrm{NaHCO}_{3} \mathrm{pH} 8.2$} \\
\hline $4^{\circ} \mathrm{C}$ & $2.5 \pm 0.06$ & $2.2 \pm 0.11$ & $1.7 \pm 0.16$ & $2.1 \pm 0.23$ \\
\hline $37^{\circ} \mathrm{C}$ & $2.3 \pm 0.13$ & $2.5 \pm 0.03$ & $2.0 \pm 0.11$ & $2.6 \pm 0.03$ \\
\hline
\end{tabular}

Note: Data are mean \pm SEM $(n=3)$.

Abbreviations: NC, nanocarrier; PBS, phosphate-buffered saline; SEM, standard error of the mean.

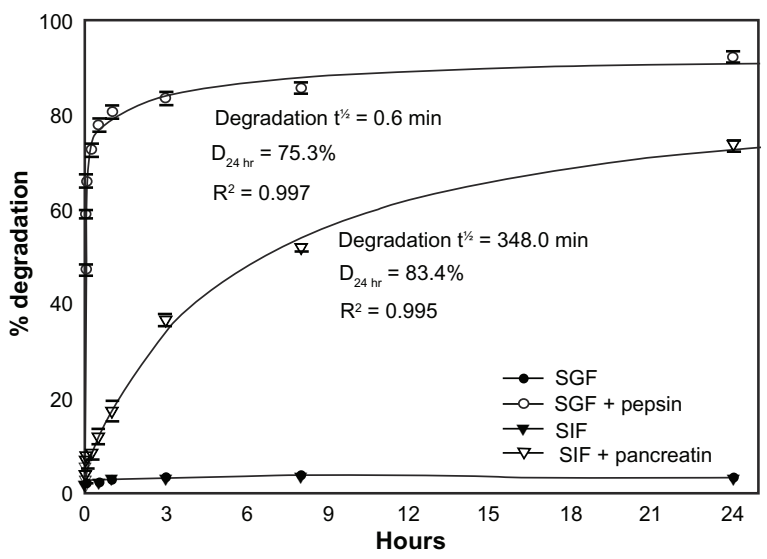

Figure 2 In vitro degradation of $\lg G$ under GI-mimicking conditions. ${ }^{125}$ - $\lg G$ was incubated for the indicated time periods in SGF with or without pepsin, or SIF with or without pancreatin, and the percentage of ${ }^{125} \mathrm{I}-\lg \mathrm{g}$ degradation was calculated as described in Figure I. Curves were fitted by software regression analysis.

Note: Data are mean \pm SEM ( $n \geq 3$ per experiment and at least two independent experiments).

Abbreviations: SGF, simulated gastric fluid; SIF, simulated intestinal fluid; SEM, standard error of the mean.

\section{Biodistribution and degradation of IgG- coated nanocarriers in the Gl tract}

Apart from direct coupling of drugs to targeting moieties such as antibodies, antibody-coated NCs are commonly explored for drug targeting. However, antibody-coated NCs display targeting and biodistribution patterns different from free antibodies due to differences in size and valency (which determines avidity), among other parameters. ${ }^{45,51}$ We therefore assessed the biodistribution of IgG-coated polymer NCs in the GI tract of mice, compared to that of free IgG. A detailed characterization of IgG NCs, compared to uncoated NCs, is provided in Table 1. Briefly, each NC presented $\sim 260 \mathrm{IgG}$ molecules on the coat, with a final size $\sim 270 \mathrm{~nm}$, polydispersity index $\sim 0.3$, and zeta-potential $\sim-7 \mathrm{mV}$ in PBS. These particles showed spherical morphology when visualized by electron microscopy (data not shown), as described previously. ${ }^{43,45}$

Imaging of mice gavaged with fluorescently-labeled IgG NCs revealed an early accumulation in proximal GI compartments (similar to free IgG), progressing to more distal accumulation over time (Figure S1). As with free IgG, no fluorescence was detected within the cecum or colon (data not shown). Examination of mouse GI sections isolated 1 hour after oral gavage with ${ }^{125} \mathrm{I}$-labeled IgG NCs (Figure 3A) showed that gastric retention was significantly greater for ${ }^{125} \mathrm{I}-\mathrm{IgG}$ NCs compared to ${ }^{125} \mathrm{I}$-IgG (1.7-fold enhancement). The opposite effect was found in the case of the jejunum (3.6-fold reduction). Both ${ }^{125} \mathrm{I}-\mathrm{IgG}$ and ${ }^{125} \mathrm{I}-\mathrm{IgG}$ NCs formulations led to similar accumulation in the duodenum $(1.08 \% \pm 0.27 \%$ ID and 


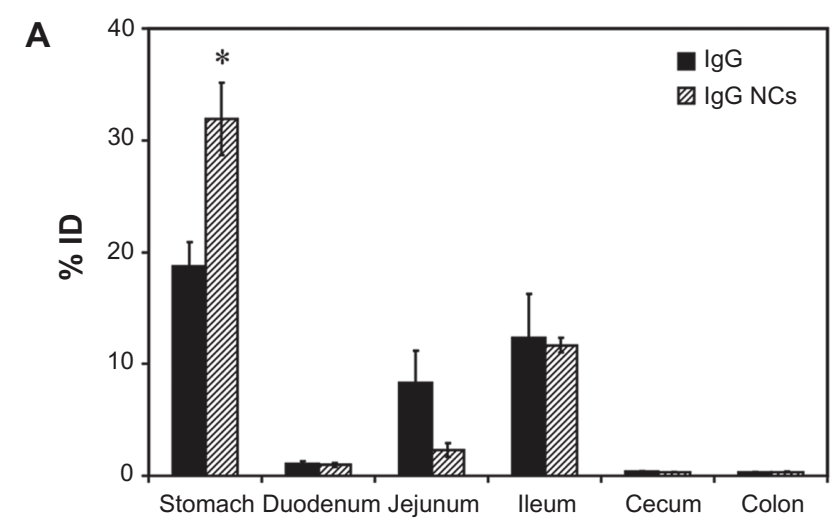

B

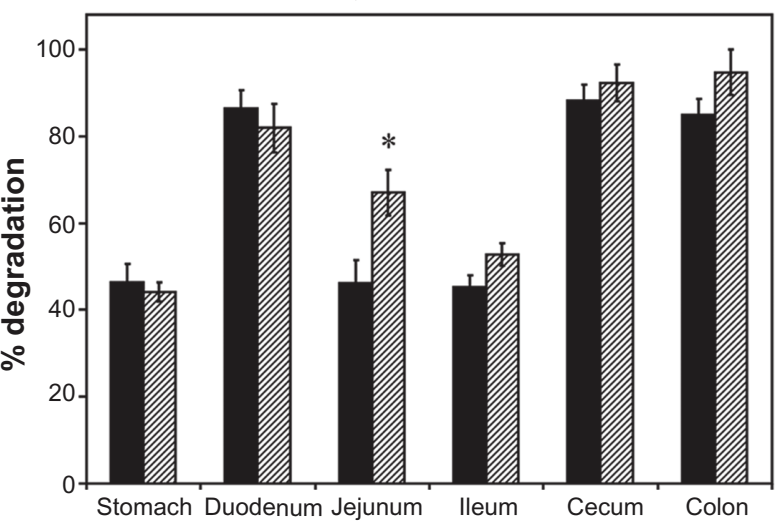

Figure 3 Biodistribution and degradation of $\lg \mathrm{g}$ nanocarriers in the $\mathrm{Gl}$ tract. Mice were gavaged with ${ }^{125} \mathrm{I}-\mathrm{lgG}$-coated model polymer NCs (IgG NCs) in PBS, final diameter $269.8 \pm 6.3 \mathrm{~nm}$, and compared to their ${ }^{125} \mathrm{I}-\mathrm{lgG}$ counterparts. One hour later, the indicated sections of the Gl tract were harvested and measured for their ${ }^{125}$ I-content, expressed as \% ID (A). Samples were also subjected to TCA precipitation to determine the percentage of free ${ }^{125}$ lodine, reflective of degradation (B).

Notes: Data are mean \pm SEM $(n \geq 3)$. ${ }^{*} P<0.05$ between IgG and IgG NC groups. Abbreviations: GI, gastrointestinal; NC, nanocarrier; PBS, phosphate-buffered saline; \% ID, percentage of the total injected dose; TCA, trichloroacetic acid; SEM, standard error of the mean.

$0.98 \% \pm 0.2 \%$ ID, respectively) and ileum $(12.3 \% \pm 3.94 \%$ ID and $11.7 \% \pm 0.65 \%$ ID, respectively). Neither formulation migrated substantially to the cecum or colon $(<1 \%$ ID).

The pattern of degradation of the antibody coat of ${ }^{125} \mathrm{I}-$ IgG NCs (Figure 3B) closely resembled that of free ${ }^{125} \mathrm{I}-\mathrm{IgG}$, with $\geq 80 \%$ degradation found in the duodenum, cecum and colon, and $\sim 40 \%-50 \%$ stability found in the stomach and ileum. While the fraction of ${ }^{125} \mathrm{I}-\mathrm{IgG}$ NCs found in the jejunum was reduced as compared to free ${ }^{125} \mathrm{I}-\mathrm{IgG}$ (Figure $3 \mathrm{~A}$ ), IgG NCs showed a higher percentage of degradation (1.5-fold increase; Figure 3B). Counterintuitively, then, ${ }^{125} \mathrm{I}-\mathrm{IgG}$ coated on NCs appears to be more susceptible to degradation than its free ${ }^{125} \mathrm{I}-\mathrm{IgG}$ counterpart. As in the case of ${ }^{125} \mathrm{I}-\mathrm{IgG}$, degradation of ${ }^{125} \mathrm{I}-\mathrm{IgG} \mathrm{NCs}$ may be predominantly enzymatic, considering that administration in $\mathrm{NaHCO}_{3}$ did not affect the degradation pattern of ${ }^{125} \mathrm{I}-\mathrm{IgG} \mathrm{NCs}$ (except for the stomach, where degradation actually increased 1.5-fold; Figure S3B). However, $\mathrm{NaHCO}_{3}$ did promote distal migration of ${ }^{125} \mathrm{I}-\mathrm{IgG} \mathrm{NCs}$ similarly to the effect on ${ }^{125} \mathrm{I}-\mathrm{IgG}$ seen in Figure 1A, resulting in lower gastric retention (2.3-fold reduction) and enhanced ileal accumulation (1.8-fold enhancement) (Figure S3A).

\section{Enzyme- and $\mathrm{pH}$-dependent degradation of IgG nanocarriers in vitro}

As with free ${ }^{125} \mathrm{I}-\mathrm{IgG}$ described above, we examined the stability of ${ }^{125} \mathrm{I}-\mathrm{IgG}$ NCs in vitro. First, we determined how SGF (pH 1.1) and SIF (pH 6.8) affected the size, polydispersity, and zeta potential of these NCs. As shown in Table 1, incubation in SGF shifted the zeta-potential of IgG NCs and uncoated NCs to more positive values, and the opposite effect was found under incubation with SIF, in agreement with the $\mathrm{pH}$ of these solutions. Interestingly, in the case of IgG NCs incubated with SGF (but not SIF) a large increase in the NC size was found, which may be due to protonation of the $\mathrm{IgG}$ coating and/or partial antibody denaturation at acidic $\mathrm{pH}$ with aggregation. The polydispersity index also decreased in SGF, indicating that this effect was uniform through the NC population. The NC size of control uncoated NCs was not altered by SGF or SIF, confirming that the IgG NC size increase in SGF was due to changes in the antibody coating.

In addition, neither $\mathrm{pH}$ nor temperature caused significant degradation of the antibody coat of ${ }^{125} \mathrm{I}-\mathrm{IgG} \mathrm{NCs}$ ( $<3 \%$ degradation, Table 2 ). A similar lack of degradation $(<3.8 \% \pm 1.0 \%$; Figure 4$)$ was observed even after incubation for 24 hours at $37^{\circ} \mathrm{C}$ in SGF at pH 1.1 or SIF at pH 6.8. However, the presence of pepsin within SGF or pancreatin

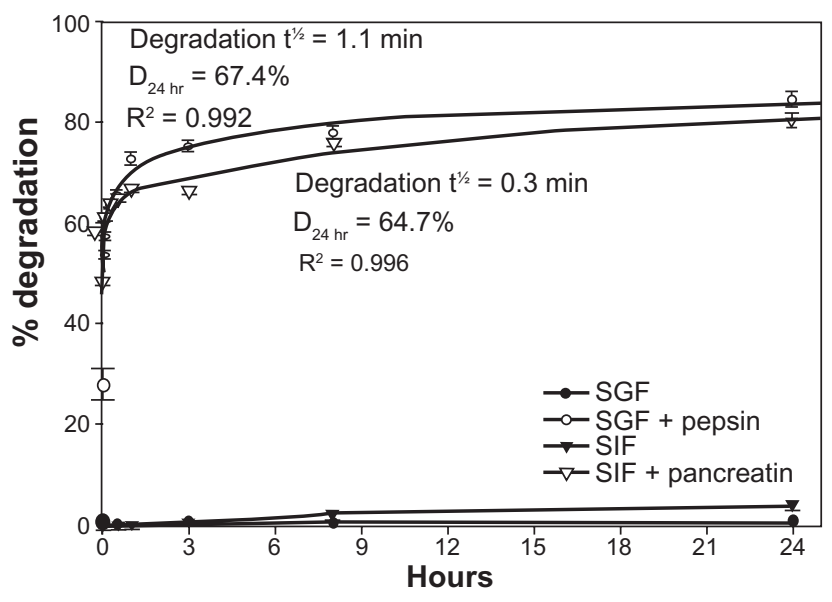

Figure 4 In vitro degradation of IgG nanocarriers under Gl-mimicking conditions. ${ }^{125}$ |-IgG NCs were incubated for the indicated time periods in SGF \pm pepsin or SIF \pm pancreatin, followed by TCA precipitation to determine the percentage of free ${ }^{125}$ lodine, reflective of degradation, as described in Figure I. Curves were fitted by software regression analysis.

Note: Data are mean \pm SEM ( $n \geq 3$ per experiment and at least two independent experiments).

Abbreviations: GI, gastrointestinal; NC, nanocarrier; SGF, simulated gastric fluid; SIF, simulated intestinal fluid; TCA, trichloroacetic acid; SEM, standard error of the mean. 
within SIF resulted in rapid degradation of ${ }^{125} \mathrm{I}-\mathrm{IgG}$ on the NC coat, with $t^{1} / 2$ of 1.1 minutes and 0.3 minutes, respectively. Degradation by either pepsin or pancreatin reached a plateau between 1 and 3 hours, with $\mathrm{D}_{24 \mathrm{hr}}$ of $67.4 \%$ and $64.7 \%$, respectively. Hence, as in the case of free ${ }^{125} \mathrm{I}-\mathrm{IgG},{ }^{125} \mathrm{I}-\mathrm{IgG}$ on the $\mathrm{NC}$ coat is also susceptible to enzymatic, but not $\mathrm{pH}$-dependent degradation. Furthermore, ${ }^{125} \mathrm{I}$-IgG NCs seem more susceptible to intestinal degradation than ${ }^{125} \mathrm{I}-\mathrm{IgG}$ (Figures 2 and 4). This supports our previous observation showing greater degradation of ${ }^{125} \mathrm{I}-\mathrm{IgG} \mathrm{NCs}$ than ${ }^{125} \mathrm{I}-\mathrm{IgG}$ in the jejunum in vivo (Figure 3B).

\section{ICAM-I targeting in the Gl tract}

Rat IgG represents a nonspecific control expected to bind with minimal, if any, affinity for mouse GI surface determinants, and also provides an isotype control for nonspecific cross-reactivity to murine Fc-receptors. The results obtained regarding biodistribution of $\mathrm{IgG}$ or $\mathrm{IgG}$ NCs therefore reflect passive GI transit. However, our findings also show some retention in proximal GI regions. We next determined whether GI targeting by specific antibodies could further modify this proximal retention. To test this, we examined GI biodistribution of anti-ICAM and anti-ICAM NCs, since ICAM-1 is expressed on the luminal surface of GI epithelial cells. ${ }^{35,36}$

Our previous experiments using non-specific counterparts showed no accumulation of antibodies or antibody-coated $\mathrm{NCs}$ in the cecum and colon $(<1 \%$ ID and $\geq 96.7 \%$ degradation; Figure 3). Hence, we decided to group GI compartments as stomach, duodenum, and the remainder of intestinal sections ("distal") for simplicity. As shown in Figure 5A, oral gavage with anti-ICAM resulted in a significantly greater retention compared to nonspecific $\operatorname{IgG}$ in the stomach (1.6-fold increase) and the duodenum (2.9-fold increase), while distal accumulation was consequently decreased (1.9-fold decrease).

We next compared the biodistribution of anti-ICAM NCs against that of IgG NCs (Figure 5B). Anti-ICAM NCs also showed enhanced retention in the stomach (1.6-fold increase) and duodenum (3.9-fold increase), resulting in reduced accumulation in distal compartments (2.8-fold decrease). When compared to free anti-ICAM (Figure 5C), anti-ICAM NCs displayed a 1.8-fold increase in gastric retention and a 2.0-fold decrease in distal distribution, with no apparent changes in the accumulation in the duodenum.

These results are consistent with both a size- and valencydependent distribution pattern, where larger NCs (which also present more ICAM-1 binding motifs) may move more slowly
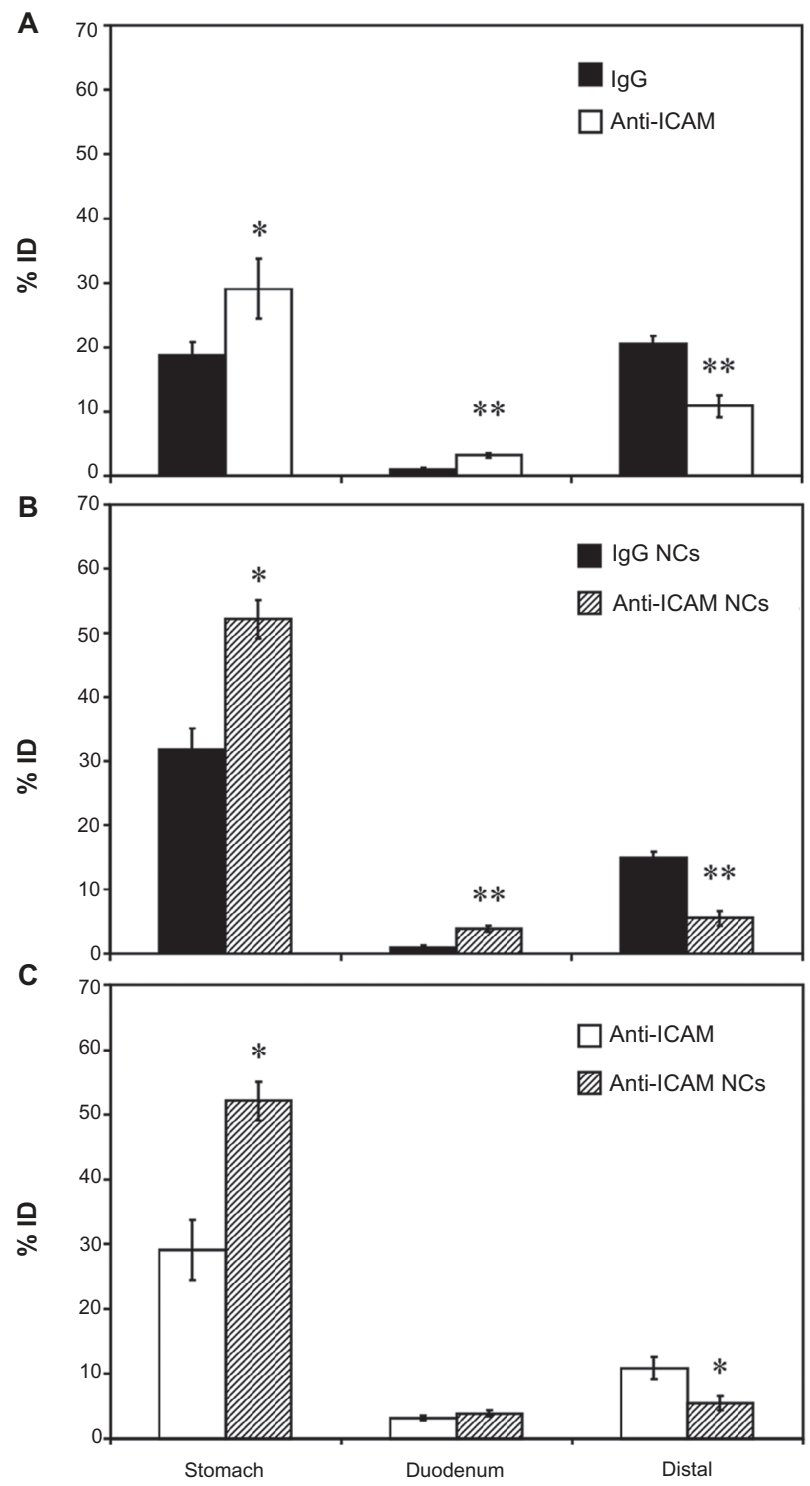

Figure 5 Biodistribution of anti-ICAM and anti-ICAM nanocarriers in the GI tract. Mice were gavaged with PBS containing ${ }^{125}$-anti-ICAM vs ${ }^{125}$ I-IgG $(\mathbf{A})$ or ${ }^{125}$-anti-ICAM NCs vs ${ }^{125} \mathrm{I}-\lg$ GCs (B), and ${ }^{125}$ lodine biodistribution in the stomach, duodenum, and distal GI regions (encompassing jejunum, ileum, cecum, and colon) was assessed one hour later as described in Figure I. A comparison of the biodistribution of ${ }^{125}$ I-anti-ICAM vs ${ }^{125}$-anti-ICAM NCs is shown in (C).

Notes: Results are expressed as \% ID. Data are mean \pm SEM, $(n \geq 3)$. (A) and (B) $* P<0.05 ; * *<<0.005$ between nontargeting IgG and ICAM-targeting groups. (C) $* P<0.05$ between anti-ICAM free antibody and anti-ICAM NCs.

Abbreviations: ICAM, intercellular adhesion molecule; GI, gastrointestinal; PBS, phosphate-buffered saline; NC, nanocarrier; \% ID, percentage of the total injected dose; SEM, standard error of the mean.

through the GI tract. Indeed, gastric accumulation of antiICAM NCs held steady between 30 minutes $(49.6 \% \pm 4.2 \%$ ID) and 1 hour $(52.1 \% \pm 3.0 \%$ ID), then dropped by 3 hours after oral gavage $(5.7 \% \pm 0.7 \%$ ID; Figure S4A). Duodenal accumulation also decreased over time $(9.0 \% \pm 1.5 \%$ ID at 30 minutes versus $1.4 \% \pm 0.2 \%$ ID at 3 hours) while distal accumulation increased $(1.4 \% \pm 0.2 \%$ ID at 30 minutes versus $8.0 \% \pm 0.5 \%$ ID at 3 hours). Biodistribution was also 
shifted toward distal compartments by oral gavage of antiICAM NCs in $\mathrm{NaHCO}_{3}$ versus PBS (Figure S4B): $\mathrm{NaHCO}_{3}$ reduced stomach retention 3.5-fold and increased distal accumulation 11.1-fold.

\section{Visualization of anti-ICAM nanocarriers in Gl tissue}

Enhanced proximal (gastric + duodenal) retention of antiICAM and anti-ICAM NCs, compared to nonspecific controls, suggests binding to ICAM-1 on the surface of GI tissue. To demonstrate binding to ICAM-1, we collected cross-sectional tissue fragments from various GI compartments 15 minutes after oral gavage with fluorescent antiICAM NCs, and thoroughly washed away unbound NCs. Microscopic analysis (Figure 6) showed that fluorescence intensity was greatest in the stomach and tapered off distally, supporting the proximal retention described for radiolabeled anti-ICAM NCs (Figure 5B).

To examine attachment of anti-ICAM NCs to GI epithelial tissue and potential internalization within cells, we used anti-ICAM-coated iron oxide NCs to facilitate visualization by TEM and EDS. Although the outer silica shell of the iron oxide NCs was not visible by TEM, we detected the inner iron oxide core of these NCs which corresponds to electron-dense spheres of $\sim 20 \mathrm{~nm}$ in diameter (Figure S5, left column). EDS analysis verified the presence of iron and oxygen (elemental components of iron oxide NCs) colocalizing with electrondense particles visualized by TEM, while neither calcium (negative control) nor carbon (used as a protective coating on

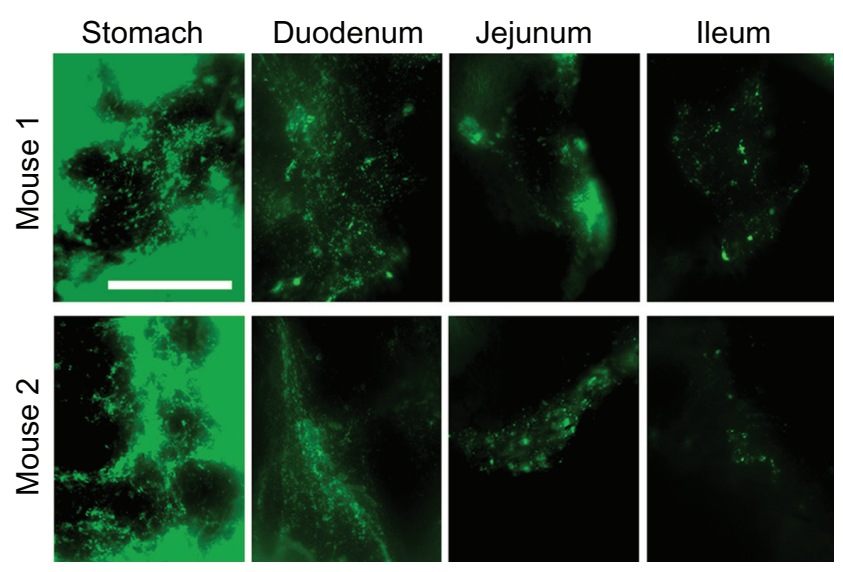

Figure 6 Visualization of anti-ICAM nanocarriers bound to Gl tissue. Mice were gavaged with FITC-labeled anti-ICAM NCs in PBS, then euthanized after 15 minutes. Cross-sectional dissections were made in the stomach, duodenum, jejunum, and ileum.

Notes: Dissected tissue was thoroughly rinsed to remove unbound NCs and imaged by microscopy to detect tissue-associated fluorescent NCs. Scale bar $=500 \mu \mathrm{m}$. Abbreviations: ICAM, intercellular adhesion molecule; GI, gastrointestinal; NC, nanocarrier; PBS, phosphate-buffered saline. the grid) showed specific colocalization with NCs, validating this method of NC detection.

Similarly, in duodenal specimens obtained from mice gavaged with anti-ICAM iron oxide NCs, electron-dense regions were found within vesicular compartments in GI epithelial cells (arrows in Figure 7H). These compartments colocalized with iron (arrows in Figure 7I) and oxygen signatures (arrow in Figure S5, right column), indicating endocytosis of anti-ICAM NCs by GI epithelial cells. The specificity of iron and oxygen signatures was in contrast to calcium and carbon signatures, which did not co-localize with intracellular vesicles (arrows in Figure S5, right column).

As expected, electron-dense, iron positive compartments were not detected in control mice orally gavaged with saline (upper panels in Figure 7). In both control mice and antiICAM NC-treated mice, non-vesicular regions lacked both electron-dense patterns (arrowheads in Figure 7B and E) and iron EDS signatures (arrowheads in Figure 7C, F, and I). Also, these control regions presented non-specific distribution of oxygen, calcium, and carbon (arrowheads in Figure S5, right). In contrast to Figure $7 \mathrm{H}$ and I, both control mice and anti-ICAM NC-treated mice also presented electron-dense vesicular compartments (arrows in Figure 7B and E) voided of iron signatures (arrows in Figure 7C and F). These compartments likely correspond to lysosomes. Taken together, these results demonstrate uptake of anti-ICAM NCs by epithelial cells in the GI tissue after oral gavage in mice.

\section{Discussion}

Targeting strategies may involve the coupling of therapeutic compounds to affinity moieties or loading into NCs that display targeting moieties on their surface. Such strategies are increasingly explored in GI drug delivery for pathologies affecting GI tissue, as well as to improve absorption of orally-delivered drugs into the circulation. ${ }^{1,2,33,52}$ We have examined the biodistribution, stability, binding, and uptake of orally administered antibodies, delivered as either free entities or coated onto the surface of NCs. We have also compared nontargeting antibodies to antibodies targeting the cell surface determinant ICAM-1. ICAM-1 was selected based on: (a) its presence on GI epithelial cells ${ }^{35,36}$ and overexpression under GI pathology:36-39 (b) its ability to mediate binding and endocytosis of drug conjugates and carriers; ${ }^{46}$ and (c) prior literature on ICAM-1-targeting in cell culture and in vivo. ${ }^{41-44,47}$ We utilized model polystyrene NCs since: (a) polymer-based carriers are stable in the GI environment compared to other formulations; ${ }^{7,33}$ (b) anti-ICAM coated 
TEM
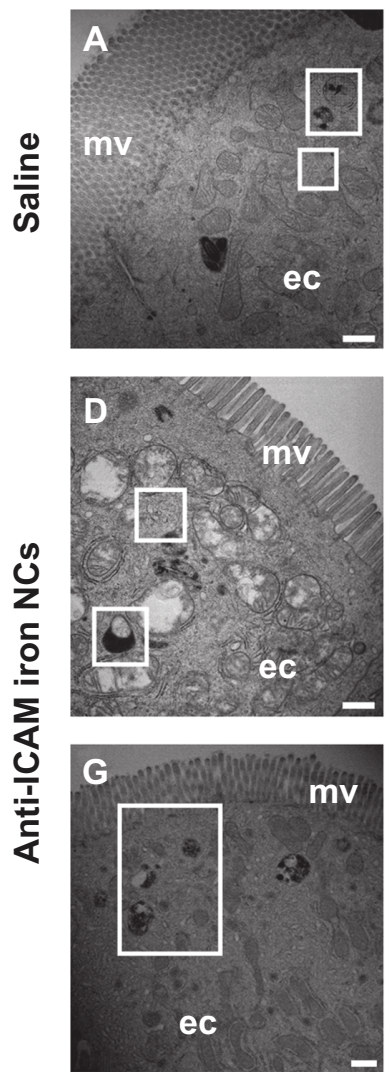

TEM
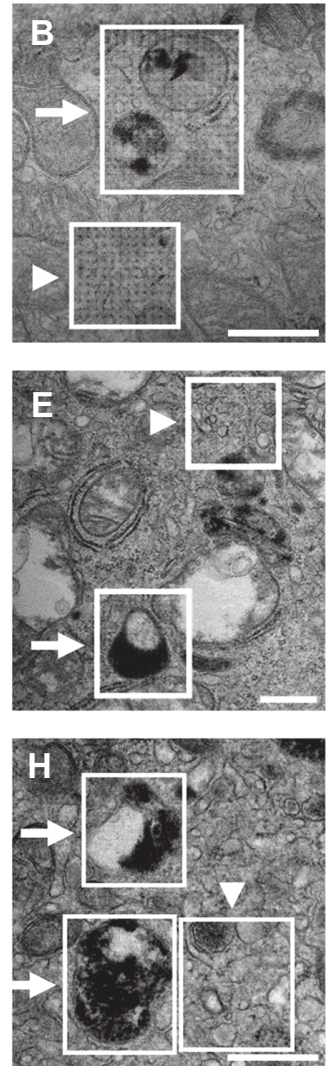

Iron EDS
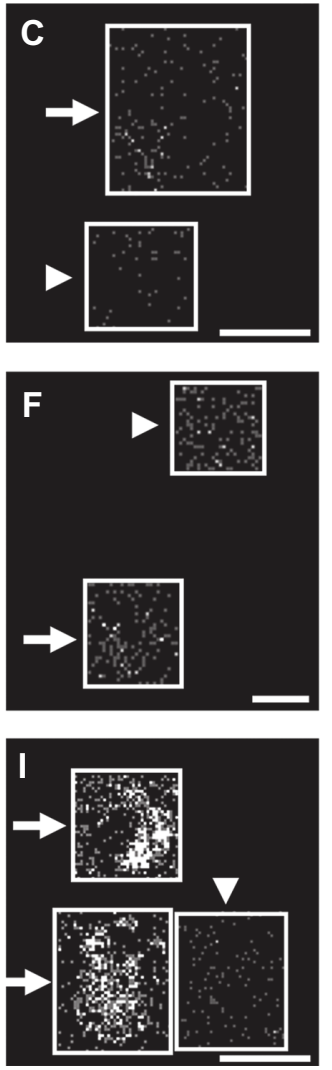

Figure 7 Visualization of epithelial endocytosis of anti-ICAM nanocarriers into GI tissue. Mice were gavaged with saline (A-C) or anti-ICAM-coated iron oxide nanoparticles suspended in $\mathrm{NaHCO}_{3}$ (D-I).

Notes: GI tissue was isolated after 10 minutes, processed, and imaged by TEM and iron EDS. In each row, a lower-magnification TEM image of the duodenum (left) is followed by a higher-magnification TEM image (middle) and its corresponding EDS analysis (right). White boxes indicate regions of EDS analysis. Arrows indicate electron-dense vesicular structures while arrowheads indicate non-vesicular structures. Scale bar $=500 \mathrm{~nm}$.

Abbreviations: mv, microvilli; ec, enterocyte; ICAM, intercellular adhesion molecule; GI, gastrointestinal; TEM, transmission electron microscope; EDS, energy dispersive X-ray spectroscopy.

polystyrene NCs display similar targeting and uptake as biocompatible, translationally relevant poly(lactic-coglycolic acid) $\mathrm{NCs}^{51}$ and (c) the transit and kinetics of polystyrene particles in mucosal environments has been described. ${ }^{26,53,54}$

After gastric gavage, free antibodies and their NCs counterparts were detected preferentially in the stomach, the jejunum, and the ileum, compared to the duodenum and distal areas of the GI tract. Downstream transit was time-dependent, and inhibiting peristalsis by sedation ${ }^{55}$ increased proximal retention of antibodies, while decreasing mucosal viscosity ${ }^{56}$ with $\mathrm{NaHCO}_{3}$ enhanced distal passage. Hence, the distribution of both nonspecific and ICAM-1-targeting formulations seems substantially controlled by passive transit through the GI tract. ${ }^{6,9}$ This result was expected due to the presence of the mucus lining. ${ }^{6,9}$ This layer extends between $10 \mu \mathrm{m}$ (ileum) and $>150 \mu \mathrm{m}$ (stomach) above the epithelial tissue, with a relatively "unstirred" coating above the cell surface and a luminal "sloppy" layer that is cleared by peristalsis every 4-6 hours. , $^{6}$ This represents a considerable barrier for drug delivery and uptake. ${ }^{6,9}$ Many compounds, pathogens and other objects are mechanically entrapped in the mucus mesh and also associate with it via hydrogen bonding, van der Waals forces, and hydrophobic or electrostatic interactions. ${ }^{6,9}$ This has been reported for "naked" polystyrene and other nanoparticles, which adhere to mucin fibers, penetrate minimally across the mucus mesh, and are cleared by fecal elimination. ${ }^{6,9}$ The use of lectins for epithelial binding is also suboptimal due to strong association with mucus. ${ }^{57}$

However, both free anti-ICAM and anti-ICAM NCs showed significant additional retention in proximal regions of the GI tract and reduced transit to distal regions when compared to control IgG counterparts, particularly in the stomach and duodenum. This indicates that targeting to GI tissue is feasible, which can potentially be translated into clinical applications, eg, by using humanized antibodies, their 
fragments, or other affinity moieties. Such targeting may be in part explained by the length of the extracellular domain of ICAM-1, as compared to that of other determinants on the GI surface. This parameter is important because it impacts accessibility, particularly in the case of bulky drug delivery systems versus small soluble ligands. For instance, coupling of particles to cholera toxin B in order to target ganglioside GM1 on the cell surface induced efficient GI binding only in the case of $6 \mathrm{~nm}$ diameter particles. ${ }^{58}$ However, binding was reduced for $30 \mathrm{~nm}$ particles and totally eliminated for $1 \mu \mathrm{m}$ particles, despite the greater avidity of the larger counterparts. ${ }^{58}$ This was due to steric hindrance leading to limited accessibility to GM1, as this determinant protrudes only $2.5 \mathrm{~nm}$ from the cell membrane..$^{9,58}$ In comparison, ICAM-1 extends $\sim 18 \mathrm{~nm}$ from the membrane. ${ }^{59}$

Mucus penetration of antibodies and antibody-coated $\mathrm{NCs}$ may be due to their surface properties. For instance, IgG and IgA antibodies display minimal hindrance to diffusion in mucus due to the high density of charged residues on these molecules (despite a neutral net charge). ${ }^{49}$ Also, pentameric IgM antibodies diffuse well through mucus despite their relatively large size. ${ }^{50}$ Clinically, immunoglobulins have been administered orally to treat viral gastroenteritis; these antibodies survive in the GI tract and induce functional immunization. ${ }^{60}$ The same surface property is exploited by certain pathogens in order to avoid mucoadhesive entrapment and improve penetration toward the epithelial lining. ${ }^{6,9}$ It appears that anti-ICAM NCs can similarly bypass mucus and access the GI epithelial surface, confirmed by TEM visualization of anti-ICAM NCs internalized into epithelial cells. It is possible that targeting can be further improved by facilitating penetration through low viscosity pores within mucus using materials such as chitosan, ${ }^{18,19}$ polyethylene glycol, ${ }^{12,26}$ surfactants, ${ }^{27,28}$ or mucolytic agents. ${ }^{6,9,29}$ These strategies have been shown to allow significant penetration of polystyrene and poly(lacticco-glycolic acid) particles up to $500 \mathrm{~nm}$ in size. ${ }^{26}$

ICAM-1 targeting and uptake in GI tissue is also in accord with our recent study showing efficient binding and endocytosis of anti-ICAM NCs in Caco-2 cells, which derive from human intestinal tissue. ${ }^{61}$ Our results indicate that ICAM-1 targeting may help facilitate GI retention and delivery of drugs aimed at GI maladies such as peptic ulcer, GI cancer, bacterial infection, and others. ${ }^{36-39}$ Whether these ICAM-1 targeting formulations also enter $M$ cells in the GI tract needs to be determined. This has been demonstrated for other polymer formulations (including "naked" polystyrene particles), which may be relevant in improving efficacy of oral immunization over that of soluble antigens. ${ }^{62}$
A critical consideration for drugs delivered to the GI tract is stability. In this study we focused on degradation of antibodies, and we therefore relied on nondegradable polystyrene particles. The pattern of degradation observed and lack of dependence on $\mathrm{pH}$ suggest that this primarily occurs in the stomach and small intestines, mainly mediated by enzymes. In addition, we observed an increase in size in the case of antibody-coated NCs incubated in acidic SGF (but not in nearly-neutral SIF), which may indicate either protonation of the IgG coating and/or partial denaturation at acidic $\mathrm{pH}$ with aggregation. Hence, our future studies will incorporate biocompatible materials to improve stability in the GI tract while potentially improving permeation and absorption, eg, chitosan, controlled-release hydrogels, enteric capsules employed as $\mathrm{pH}$-sensitive formulations, muco/bioadhesive conjugates, permeability enhancers, or protein delivery vehicles. $^{8,9,12,18,23,24,26-28}$

In conclusion, this work underscores the feasibility of antibody-coated NC strategies to target GI surface determinants and internalize within GI tissue via ICAM-1, which may find utility in delivery of therapeutic agents for the treatment of pathologies of the GI tract.

\section{Acknowledgments}

We thank the University of Maryland Laboratory for Biological Ultrastructure and the Nanoscale Imaging, Spectroscopy, and Properties Lab of the Maryland NanoCenter, in part supported by the NSF as a MRSEC Shared Experimental Facility. We also thank Dr Tridib Bhowmick (IBBR, University of Maryland) for determining the antibody-surface coating ratio of magnetic nanoparticles. This work was funded by the National Institutes of Health grant R01-HL98416 and the American Heart Association grant 09BGIA2450014 (SM).

\section{Disclosure}

The authors report no conflicts of interest in this work.

\section{References}

1. Park K, Kwon IC, Park K. Oral protein delivery: current status and future prospect. React Funct Polym. 2011;71(3):280-287.

2. Mrsny RJ. Modification of epithelial tight junction integrity to enhance transmucosal absorption. Crit Rev Ther Drug Carrier Syst. 2005;22(4):331-418.

3. Tuma PL, Hubbard AL. Transcytosis: crossing cellular barriers. Physiol Rev. 2003;83(3):871-932.

4. Sastry SV, Nyshadham JR, Fix JA. Recent technological advances in oral drug delivery - a review. Pharm Sci Technolo Today. 2000;3(4): 138-145.

5. Bender BG, Sazonov V, Krobot KJ. Impact of medication delivery method on patient adherence. In: Harver A, Kotses H, editors. Asthma, Health and Society. New York: Springer US; 2010:107-115. 
6. Lai SK, Wang YY, Hanes J. Mucus-penetrating nanoparticles for drug and gene delivery to mucosal tissues. Adv Drug Deliv Rev. 2009;61(2): $158-171$.

7. Plapied L, Duhem N, Des Rieux A, Préat V. Fate of polymeric nanocarriers for oral drug delivery. Curr Opin Colloid Interface Sci. 2011;16(3): 228-237.

8. Serra L, Doménech J, Peppas NA. Engineering design and molecular dynamics of mucoadhesive drug delivery systems as targeting agents. Eur J Pharm Biopharm. 2009;71(3):519-528.

9. Cone RA. Barrier properties of mucus. Adv Drug Deliv Rev. 2009; 61(2):75-85

10. van Hoogevest P, Liu X, Fahr A. Drug delivery strategies for poorly water-soluble drugs: the industrial perspective. Expert Opin Drug Deliv. 2011;8(11):1481-1500.

11. Vinogradov SV, Bronich TK, Kabanov AV. Nanosized cationic hydrogels for drug delivery: preparation, properties and interactions with cells. Adv Drug Deliv Rev. 2002;54(1):135-147.

12. Yoncheva K, Lizarraga E, Irache JM. Pegylated nanoparticles based on poly(methyl vinyl ether-co-maleic anhydride): preparation and evaluation of their bioadhesive properties. Eur J Pharm Sci. 2005;24(5): 411-419.

13. Montisci MJ, Dembri A, Giovannuci G, Chacun H, Duchêne D, Ponchel G. Gastrointestinal transit and mucoadhesion of colloidal suspensions of Lycopersicon esculentum L. and Lotus tetragonolobus lectin-PLA microsphere conjugates in rats. Pharm Res. 2001;18(6): 829-837.

14. Irache JM, Salman HH, Gamazo C, Espuelas S. Mannose-targeted systems for the delivery of therapeutics. Expert Opin Drug Deliv. 2008;5(6):703-724.

15. Bies C, Lehr CM, Woodley JF. Lectin-mediated drug targeting: history and applications. Adv Drug Deliv Rev. 2004;56(4):425-435.

16. Francis MF, Cristea M, Winnik FM. Exploiting the vitamin B12 pathway to enhance oral drug delivery via polymeric micelles. Biomacromolecules. 2005;6(5):2462-2467.

17. Salman HH, Gamazo C, Agueros M, Irache JM. Bioadhesive capacity and immunoadjuvant properties of thiamine-coated nanoparticles. Vaccine. 2007;25(48):8123-8132.

18. Hejazi R, Amiji M. Chitosan-based gastrointestinal delivery systems. $J$ Control Release. 2003;89(2):151-165

19. Prego C, Torres D, Alonso MJ. The potential of chitosan for the oral administration of peptides. Expert Opin Drug Deliv. 2005;2(5): $843-854$

20. Smith JM, Dornish M, Wood EJ. Involvement of protein kinase C in chitosan glutamate-mediated tight junction disruption. Biomaterials. 2005;26(16):3269-3276.

21. Peppas NA, Wood KM, Blanchette JO. Hydrogels for oral delivery of therapeutic proteins. Expert Opin Biol Ther. 2004;4(6): 881-887.

22. Alhaique F, Santucci E, Carafa M, Coviello T, Murtas E, Riccieri FM. Gellan in sustained release formulations: preparation of gel capsules and release studies. Biomaterials. 1996;17(20):1981-1986.

23. George M, Abraham TE. Polyionic hydrocolloids for the intestinal delivery of protein drugs: alginate and chitosan - a review. J Control Release. 2006;114(1):1-14.

24. Peppas NA, Kavimandan NJ. Nanoscale analysis of protein and peptide absorption: insulin absorption using complexation and $\mathrm{pH}$-sensitive hydrogels as delivery vehicles. Eur J Pharm Sci. 2006;29(3-4): 183-197.

25. Mundargi RC, Rangaswamy V, Aminabhavi TM. pH-Sensitive oral insulin delivery systems using Eudragit microspheres. Drug Dev Ind Pharm. 2011;37(8):977-985.

26. Lai SK, O'Hanlon DE, Harrold S, et al. Rapid transport of large polymeric nanoparticles in fresh undiluted human mucus. Proc Natl Acad Sci U S A. 2007;104(5):1482-1487.

27. Dawson M, Krauland E, Wirtz D, Hanes J. Transport of polymeric nanoparticle gene carriers in gastric mucus. Biotechnol Prog. 2004;20(3): 851-857.
28. Mura S, Hillaireau H, Nicolas J, et al. Biodegradable nanoparticles meet the bronchial airway barrier: how surface properties affect their interaction with mucus and epithelial cells. Biomacromolecules. 2011; 12(11):4136-4143.

29. Takatsuka S, Kitazawa T, Morita T, Horikiri Y, Yoshino H. Enhancement of intestinal absorption of poorly absorbed hydrophilic compounds by simultaneous use of mucolytic agent and non-ionic surfactant. Eur $J$ Pharm Biopharm. 2006;62(1):52-58.

30. El-Sayed M, Ginski M, Rhodes C, Ghandehari H. Transepithelial transport of poly(amidoamine) dendrimers across Caco-2 cell monolayers. J Control Release. 2002;81(3):355-365.

31. Torchilin V. Multifunctional and stimuli-sensitive pharmaceutical nanocarriers. Eur J Pharm Biopharm. 2009;71(3):431-444.

32. Discher DE, Eisenberg A. Polymer vesicles. Science. 2002;297(5583): 967-973.

33. des Rieux A, Fievez V, Garinot M, Schneider YJ, Préat V. Nanoparticles as potential oral delivery systems of proteins and vaccines: a mechanistic approach. J Control Release. 2006;116(1):1-27.

34. Rothlein R, Dustin ML, Marlin SD, Springer TA. A human intercellular adhesion molecule (ICAM-1) distinct from LFA-1. J Immunol. 1986; 137(4):1270-1274.

35. Parkos CA, Colgan SP, Diamond MS, et al. Expression and polarization of intercellular adhesion molecule-1 on human intestinal epithelia: consequences for CD11b/CD18-mediated interactions with neutrophils. Mol Med. 1996;2(4):489-505.

36. Huang GT, Eckmann L, Savidge TC, Kagnoff MF. Infection of human intestinal epithelial cells with invasive bacteria upregulates apical intercellular adhesion molecule-1 (ICAM)-1) expression and neutrophil adhesion. J Clin Invest. 1996;98(2):572-583.

37. Burns RC, Rivera-Nieves J, Moskaluk CA, Matsumoto S, Cominelli F, Ley K. Antibody blockade of ICAM-1 and VCAM-1 ameliorates inflammation in the SAMP-1/Yit adoptive transfer model of Crohn's disease in mice. Gastroenterology. 2001;121(6):1428-1436.

38. Watanabe T, Arakawa T, Tominaga K, Fujiwara Y, Higuchi K, Kuroki T. Neutrophil accumulation in development gastric ulcer induced by submucosal injection of endothelin-1 in rats. Dig Dis Sci. 2000;45(5):880-888.

39. Maruo Y, Gochi A, Kaihara A, et al. ICAM-1 expression and the soluble ICAM-1 level for evaluating the metastatic potential of gastric cancer. Int J Cancer. 2002;100(4):486-490.

40. Danilov SM, Gavrilyuk VD, Franke FE, et al. Lung uptake of antibodies to endothelial antigens: key determinants of vascular immunotargeting Am J Physiol Lung Cell Mol Physiol. 2001;280(6):L1335-L1347.

41. Chittasupho C, Xie SX, Baoum A, Yakovleva T, Siahaan TJ, Berkland CJ. ICAM-1 targeting of doxorubicin-loaded PLGA nanoparticles to lung epithelial cells. Eur J Pharm Sci. 2009;37(2):141-150.

42. Weller GE, Villanueva FS, Klibanov AL, Wagner WR. Modulating targeted adhesion of an ultrasound contrast agent to dysfunctional endothelium. Ann Biomed Eng. 2002;30(8):1012-1019.

43. Hsu J, Serrano D, Bhowmick T, et al. Enhanced endothelial delivery and biochemical effects of $\alpha$-galactosidase by ICAM-1-targeted nanocarriers for Fabry disease. J Control Release. 2011;149(3):323-331.

44. Sakhalkar HS, Dalal MK, Salem AK, et al. Leukocyte-inspired biodegradable particles that selectively and avidly adhere to inflamed endothelium in vitro and in vivo. Proc Natl Acad Sci U S A. 2003; 100(26):15895-15900.

45. Calderon AJ, Bhowmick T, Leferovich J, et al. Optimizing endothelial targeting by modulating the antibody density and particle concentration of anti-ICAM coated carriers. J Control Release. 2011; 150(1):37-44.

46. Muro S, Garnacho C, Champion JA, et al. Control of endothelial targeting and intracellular delivery of therapeutic enzymes by modulating the size and shape of ICAM-1-targeted carriers. Mol Ther. 2008;16(8):1450-1458.

47. Muro S, Wiewrodt R, Thomas A, et al. A novel endocytic pathway induced by clustering endothelial ICAM-1 or PECAM-1. J Cell Sci. 2003;116(Pt 8):1599-1609. 
48. Fu TJ, Abbott UR, Hatzos C. Digestibility of food allergens and nonallergenic proteins in simulated gastric fluid and simulated intestinal fluid-a comparative study. J Agric Food Chem. 2002;50(24): 7154-7160.

49. Saltzman WM, Radomsky ML, Whaley KJ, Cone RA. Antibody diffusion in human cervical mucus. Biophys J. 1994;66(2 Pt 1): 508-515.

50. Olmsted SS, Padgett JL, Yudin AI, Whaley KJ, Moench TR, Cone RA. Diffusion of macromolecules and virus-like particles in human cervical mucus. Biophys J. 2001;81(4):1930-1937.

51. Muro S, Dziubla T, Qiu W, et al. Endothelial targeting of high-affinity multivalent polymer nanocarriers directed to intercellular adhesion molecule 1. J Pharmacol Exp Ther. 2006;317(3):1161-1169.

52. El-Sayed M, Rhodes CA, Ginski M, Ghandehari H. Transport mechanism(s) of poly (amidoamine) dendrimers across Caco-2 cell monolayers. Int J Pharm. 2003;265(1-2):151-157.

53. Norris DA, Sinko PJ. Effect of size, surface charge, and hydrophobicity on the translocation of polystyrene microspheres through gastrointestinal mucin. J Appl Polym Sci. 1997;63(11):1481-1492.

54. Jani P, Halbert GW, Langridge J, Florence AT. The uptake and translocation of latex nanospheres and microspheres after oral administration to rats. J Pharm Pharmacol. 1989;41(12):809-812.

55. An YJ, Lee H, Chang D, et al. Application of pulsed Doppler ultrasound for the evaluation of small intestinal motility in dogs. J Vet Sci. 2001;2(1):71-74.
56. Kinnunen J, Tötterman S, Kaila R, Pietilä J, Linden H, Tervahartiala P. Effect of sodium bicarbonate pretreatment on barium coating of mucosa during double contrast barium meal. Rofo. 1983;139(2):199-201.

57. Lehr CM, Bouwstra JA, Kok W, Noach AB, de Boer AG, Junginger HE. Bioadhesion by means of specific binding of tomato lectin. Pharm Res. 1992;9(4):547-553.

58. Frey A, Giannasca KT, Weltzin R, et al. Role of the glycocalyx in regulating access of microparticles to apical plasma membranes of intestinal epithelial cells: implications for microbial attachment and oral vaccine targeting. J Exp Med. 1996;184(3):1045-1059.

59. Jun CD, Carman CV, Redick SD, Shimaoka M, Erickson HP, SpringerTA. Ultrastructure and function of dimeric, soluble intercellular adhesion molecule-1 (ICAM-1). J Biol Chem. 2001;276(31):29019-29027.

60. Guarino A, Canani RB, Russo S, et al. Oral immunoglobulins for treatment of acute rotaviral gastroenteritis. Pediatrics. 1994;93(1): $12-16$.

61. Ghaffarian R, Bhowmick T, Muro S. Transport of nanocarriers across gastrointestinal epithelial cells by a new transcellular route induced by targeting ICAM-1. J Control Release. June 12, 2012. [Epub ahead of print.]

62. Langer R, Cleland JL, Hanes J. New advances in microsphere-based single-dose vaccines. Adv Drug Deliv Rev. 1997;28(1):97-119. 


\section{Supplementary figures}
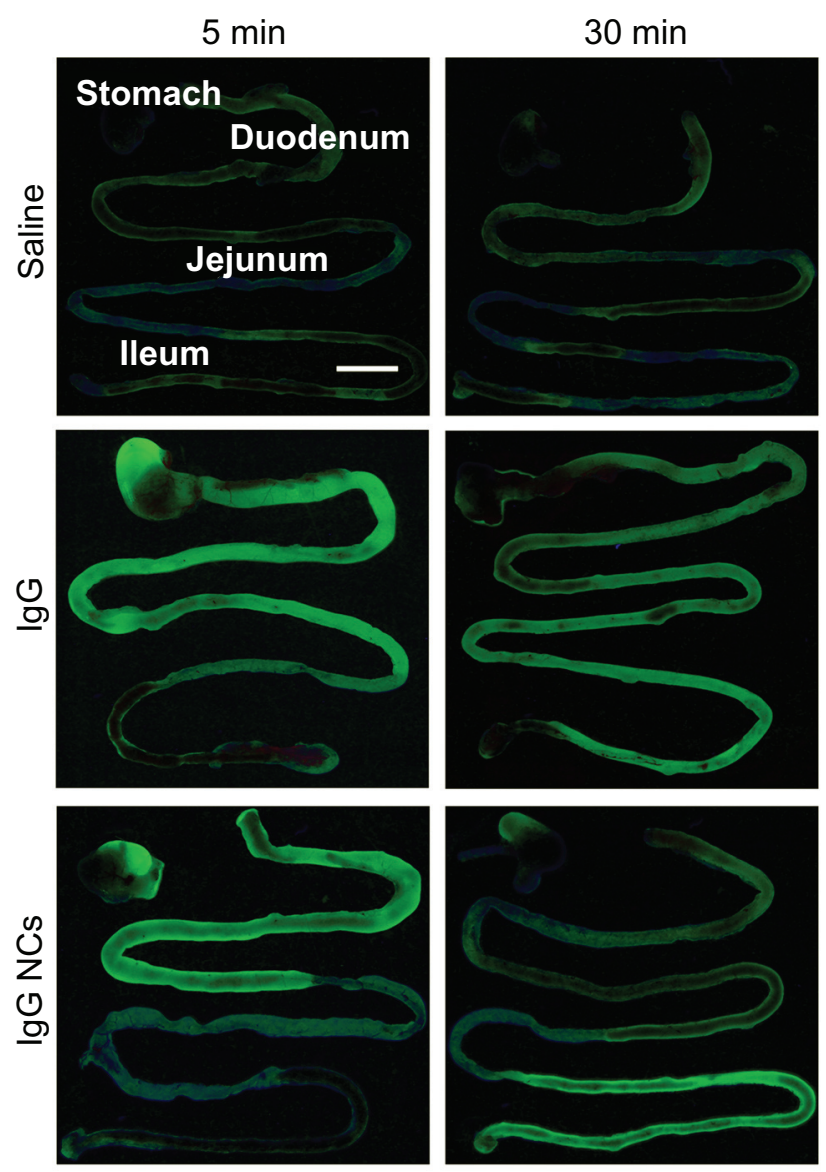

Figure SI Visualization of antibody and antibody-coated nanocarriers in the GI tract. Mice were gavaged with saline, FITC-labeled IgG, or IgG-coated NCs and sacrificed 5 minutes or 30 minutes later. Their $\mathrm{Gl}$ tracts were then excised and illuminated by UV light.

Notes: Stomach and small intestines (duodenum, jejunum, and ileum) are shown. Scale bar $=1 \mathrm{~cm}$

Abbreviations: Gl, gastrointestinal; NC, nanocarrier.
A
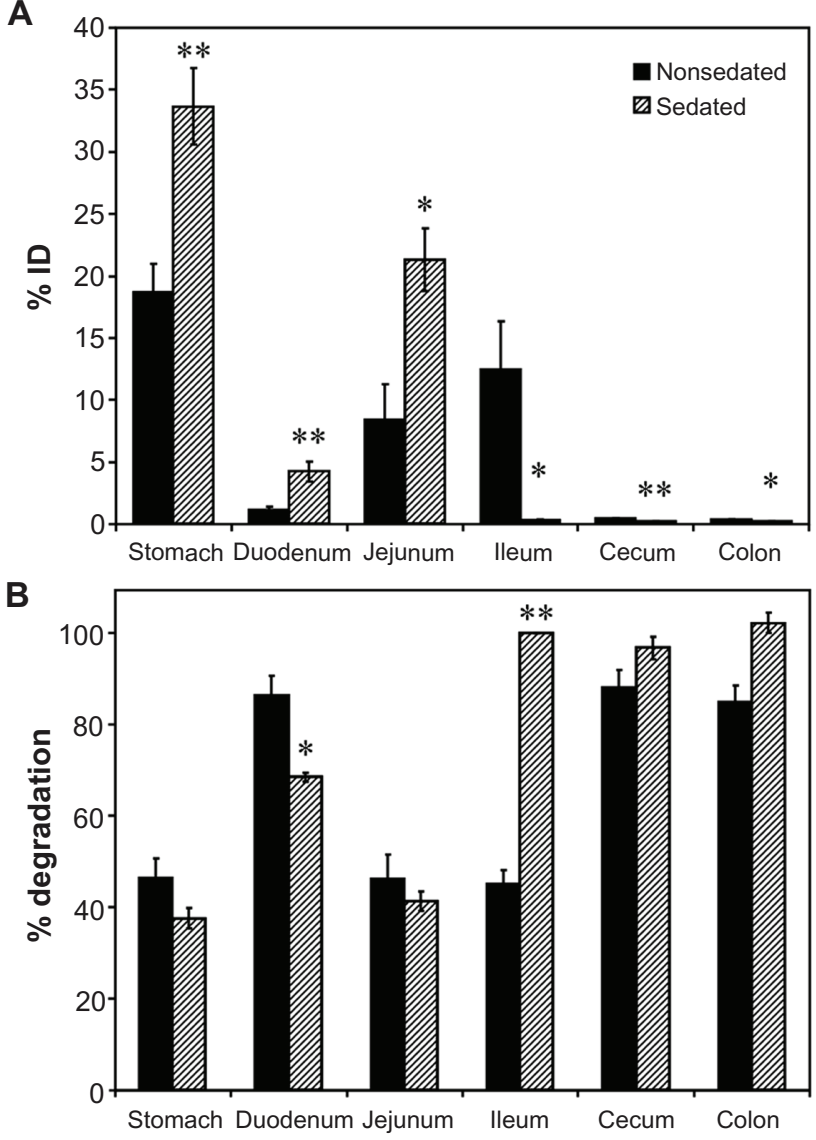

Figure S2 Effect of sedation on the GI biodistribution and degradation of ${ }^{125} \mathrm{I}-\mathrm{IgG}$ Mice were injected intraperitoneally with PBS (nonsedated) or ketamine/xylazine (sedated), then orally gavaged with ${ }^{125} \mathrm{I}-\mathrm{IgG}$ in PBS. One hour later, sections of the GI were harvested and measured for their ${ }^{125}$-content, expressed as \% ID (A). Samples were also subjected to TCA precipitation to determine the percentage of free ${ }^{125}$ lodine, reflective of antibody degradation (B)

Notes: Data are mean \pm SEM, $(n \geq 3)$. *P $<0.05$; **P $<0.005$ between sedated and nonsedated groups.

Abbreviations: GI, gastrointestinal; PBS, phosphate-buffered saline; \% ID, percentage of the total injected dose; TCA, trichloroacetic acid; SEM, standard error of the mean. 
A
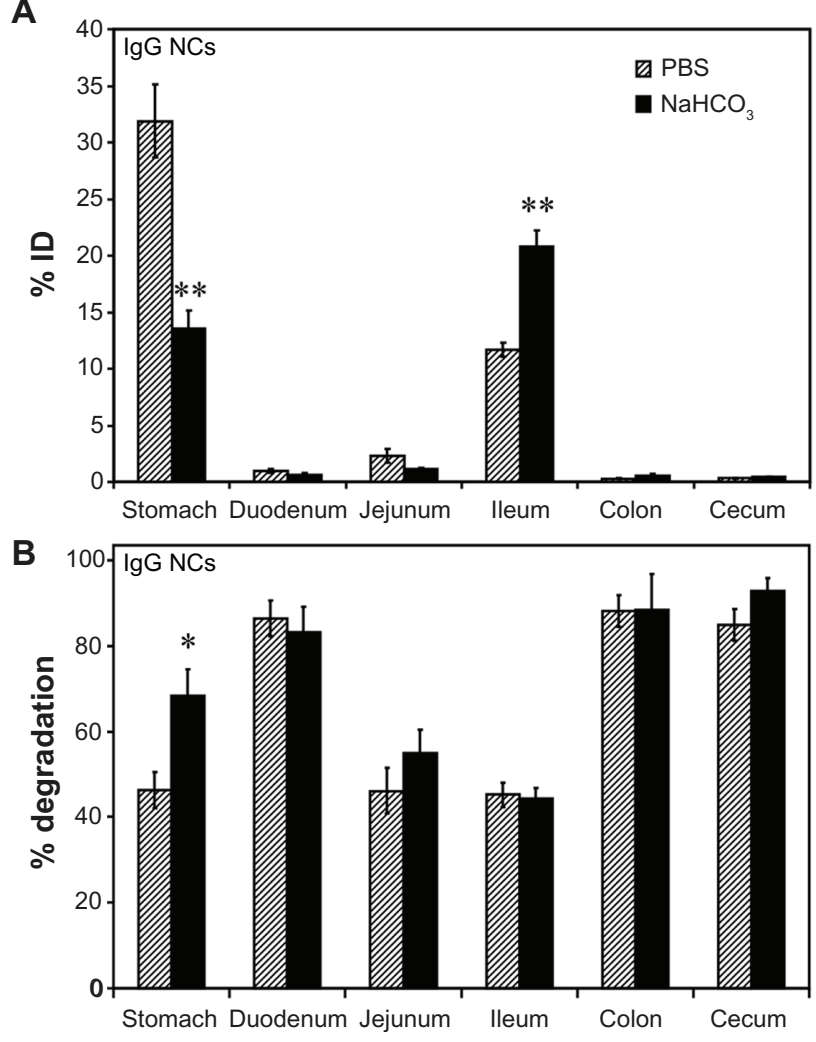

Figure S3 Effect of buffer composition on the GI biodistribution of IgG NC. Mice were gavaged with ${ }^{125} \mathrm{I} / \mathrm{lgG} \mathrm{NCs}$ in either PBS or $\mathrm{NaHCO}_{3}$. One hour later, Gl sections were harvested and measured for ${ }^{125}$-content, expressed as \% ID (A). Samples were also subjected to TCA precipitation to determine the percentage of free ${ }^{125}$ lodine, reflective of antibody degradation (B).

Notes: Data are mean \pm SEM, $(n \geq 3)$. $* P<0.05$; **P $<0.005$ between saline and $\mathrm{NaHCO}_{3}$ groups.

Abbreviations: GI, gastrointestinal; NC, nanocarrier; PBS, phosphate-buffered saline; \% ID, percentage of the total injected dose; TCA, trichloroacetic acid; SEM, standard error of the mean.
A

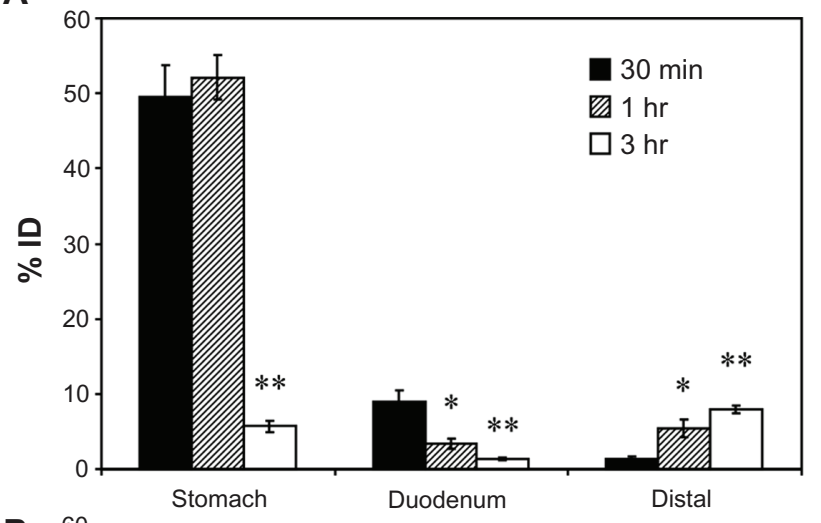

B

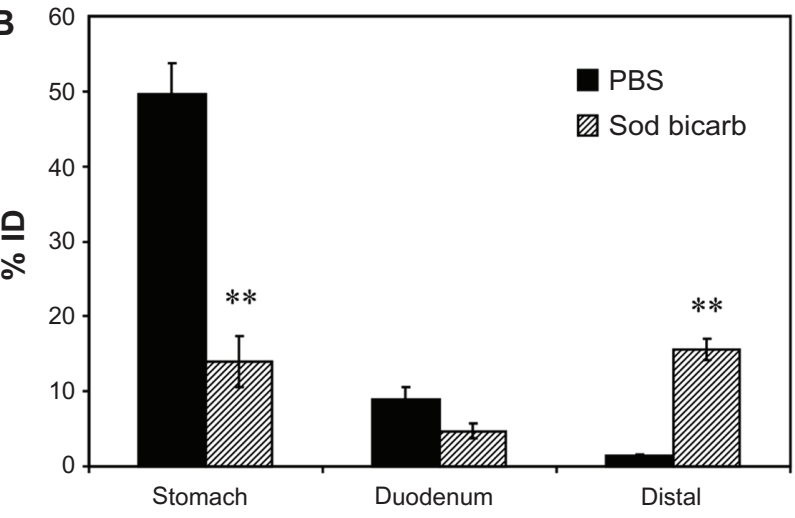

Figure S4 Biodistribution of anti-ICAM nanocarriers in the Gl tract. Mice were gavaged with ${ }^{125}$-anti-ICAM NCs in PBS and euthanized after 30 minutes, I hour, or 3 hours, followed by determination of the ${ }^{125} \mathrm{I}$-content in the stomach, duodenum, and distal intestines (encompassing the jejunum, ileum, cecum, and colon), to determine the \% ID (A). Mice were gavaged with ${ }^{125}$-anti-ICAM NCs in either PBS or $\mathrm{NaHCO}_{3}$ and euthanized after 30 minutes to determine their $\mathrm{Gl}$ biodistribution (\% ID) as described above (B).

Notes: Data are mean \pm SEM, $(\mathrm{n} \geq 3)$. (A) $* P<0.05$; * *P $<0.005$ between 30 minutes and I hour or between 30 minutes and 3 hours. (B) $* * P<0.005$ between saline and $\mathrm{NaHCO}_{3}$ groups.

Abbreviations: ICAM, intercellular adhesion molecule; GI, gastrointestinal; NC, nanocarrier; PBS, phosphate-buffered saline; \% ID, percentage of the total injected dose; SEM, standard error of the mean. 

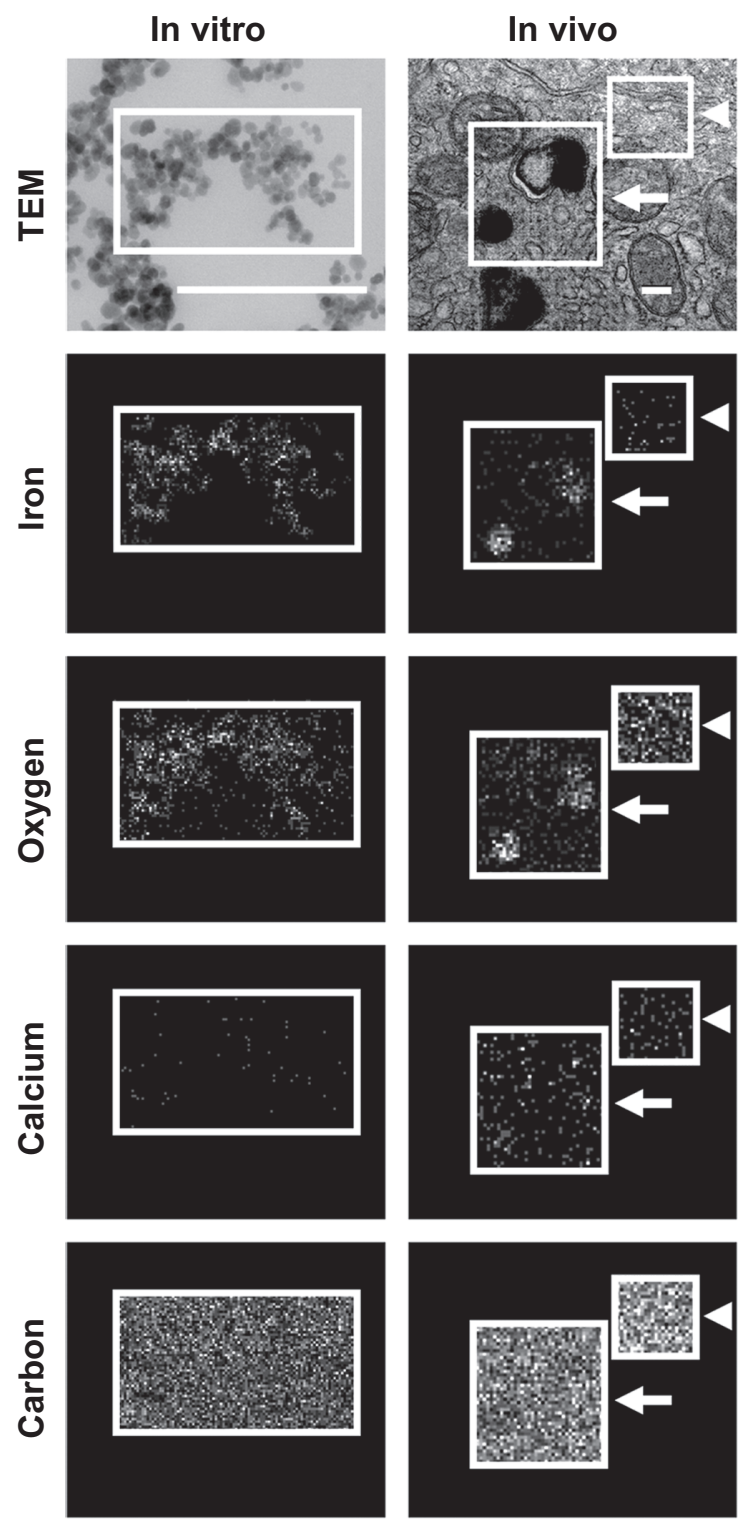

Figure S5 Visualization of anti-ICAM NCs by TEM and EDS. Antibody-coated iron oxide nanoparticles were directly coated onto microscope grids (in vitro, left column), or orally gavaged in mice followed by isolation 10 minutes later and processing of $\mathrm{Gl}$ duodenal tissue sections (in vivo, right column).

Notes: Samples were imaged by TEM (upper row) and analyzed by EDS to detect iron, oxygen, calcium, and carbon signatures. White boxes indicate the region of analysis. White arrows indicate electron-dense vesicular compartments within GI epithelial cells, while white arrowheads represent non-vesicular compartments. Scale bar $=200 \mathrm{~nm}$

Abbreviations: ICAM, intercellular adhesion molecule; TEM, transmission electron microscope; EDS, energy dispersive X-ray spectroscopy; GI, gastrointestinal.

International Journal of Nanomedicine

\section{Publish your work in this journal}

The International Journal of Nanomedicine is an international, peerreviewed journal focusing on the application of nanotechnology in diagnostics, therapeutics, and drug delivery systems throughou the biomedical field. This journal is indexed on PubMed Central, MedLine, CAS, SciSearch ${ }^{\circledR}$, Current Contents ${ }^{\circledR} /$ Clinical Medicine,

\section{Dovepress}

Journal Citation Reports/Science Edition, EMBase, Scopus and the Elsevier Bibliographic databases. The manuscript management system is completely online and includes a very quick and fair peer-review system, which is all easy to use. Visit http://www.dovepress.com/ testimonials.php to read real quotes from published authors.

\footnotetext{
Submit your manuscript here: http://www.dovepress.com/international-journal-of-nanomedicine-journal
} 